\title{
Obstruktif Uyku Apne Sendromlu Hastalarda Fibrinojen Düzeylerinin Değerlendirilmesi*
}

\author{
Ezgi DEMİRDÖĞEN, Ahmet URSAVAŞ, Mehmet KARADAĞ, Funda COŞKUN, \\ Dane EDİGER, Esra UZASLAN, Ercüment EGE, Oktay GÖZÜ
}

\author{
Bursa Uludağ Üniversitesi Tıp Fakültesi, Gögüs Hastalıkları Anabilim Dalı, Bursa.
}

\section{ÖZET}

Obstrüktif uyku apne sendromu (OUAS) hastalarında vasküler hastalık riski artmıștır. Bu hastalarda kardiyovasküler hastalık gelișimine ait kesin mekanizma bilinmemektedir. Fibrinojen normal plazmanın ana bileşenidir. Akut faz reaktanı olan fibrinojen düzeyleri inflamatuar yanıtın bir parçası olarak yükselmektedir. Fibrinojenin koroner arter hastalığı ve inme için bağımsız risk faktörü olduğu gösterilmiștir. Çalışmamızda yeni orta/ağır OUAS tanısı almış hastalarda ve non-apneik olgularda plazma fibrinojen düzeylerini karşılaştırmayı ve polisomnografi (PSG) parametreleri ile ilişkisini değerlendirmeyi amaçladık. Tüm gece PSG sonrası yeni tanı almış 50 orta ve ağır OUAS olgusu ile 33 nonapneik kontrol olgu çalışmaya dahil edilmiştir. uyku çalışmasının ardından sabah 8.00-9.00 saatleri arasında kan örnekleri alınarak plazma fibrinojen düzeyleri Clauss metodu ile ölçülmüştür. Her iki grup arasında yaş, cinsiyet, sigara alışkanlığı açısından fark saptanmadı. Plazma fibrinojen düzeyleri OUAS grubunda $(4.2 \pm 0.14 \mathrm{~g} / \mathrm{L})$ kontrol grubuna göre anlamlı derecede yüksek bulundu $(\mathrm{p}<0.028)$. Plazma fibrinojen düzeyleri; Epworth uykululuk skalası (ESS) skoru $(\mathrm{r}=0.301, \mathrm{p}=0.006)$, yaş $(\mathrm{r}=0.327, \mathrm{p}=0.003)$, beden kitle indeksi $(\mathrm{BKI})$ ( $\mathrm{r}=0.388$, $\mathrm{p}<0.001)$, ortalama oksijen desaturasyonu $(\mathrm{r}=0.258, \mathrm{p}=0.019)$, oksijen desaturasyon indeksi $(\mathrm{r}=0.281, \mathrm{p}=0.010)$, oksijen satürasyonunun \% 90 'n altında kalma süresi $(\mathrm{r}=0.248, \mathrm{p}=0.024)$ ve arousal indeksi $(\mathrm{r}=0.220, \mathrm{p}=0.046)$ ile pozitif korele idi. Plazma fibrinojen düzeyleri ile uykudaki oksijen saturasyonu arasinda $(\mathrm{r}=-0.254, \mathrm{p}=0.029)$ negatif korelasyon mevcuttu. Çoklu doğrusal regresyon analiz ile EUS skoru ve BKI'nin, AHİ'den bağımsız olarak, fibrinojen düzeyleri ile ilişkili değişkenler olduğu saptanmıştır. Sonuçta plazma fibrinojen düzeyleri ile ESS ve BKİ'nin iliş̧kili olduğu bulunmuştur. Fibrinojen düzeyleri ve nokturnal desaturasyon arasındaki ilişki, hipoksi inflamasyon ilişkisini desteklemektedir. Yüksek fibrinojen düzeylerinin OUAS'lı hastalarda vasküler hastalık gelişimi için önemli bir faktör olabileceği sonucuna varılmıştır.

Anahtar Kelimeler: Obstrüktif uyku apne sendromu (OUAS). Fibrinojen. Epworth uykululuk skalası (ESS). Hipoksi. Vasküler hastalık.

Evaluation of Fibrinogen Levels in Patients with Obstructive Sleep Apnea

\begin{abstract}
Risk of vascular disorders is increased at obstructive sleep apnea syndrome (OSAS) patients. The exact mechanism of development of vascular disease in patients with OSAS remains to be unknown. Fibrinogen is a major constituent of normal plasma. Fibrinogen is an acute phase reactant, with increasing levels as part of the of the acute inflammatory response. Fibrinogen has been shown to be an independent risk factor for coroner heart disease and stroke. Our aim was to compare plasma fibrinogen levels between OSAS and control groups, and relationship with polysomnograhy (PSG) parameters. Fifty patients with newly diagnosed moderate and severe OSAS and 33 non-apneic control subjects were enrolled in this study. Full-night PSG was performed in all patients. Blood samples were drawn at 8:00-9:00 am after the sleep study. Fibrinogen levels were analyzed with Clauss method. There were no significant differences in age, gender, smoking habit between the two groups. Plasma fibrinogen levels in the OSAS group $(4.2 \pm 0.14 \mathrm{~g} / \mathrm{L})$ were significantly higher than that in the control group $(\mathrm{p}<0.028)$. Plasma fibrinogen levels were positively correlated with Epworth sleepiness scale (ESS) ( $r=0.301, \mathrm{p}=0.006)$, age $(\mathrm{r}=0.327$, $\mathrm{p}=0.003)$, body mass index (BMI) $(\mathrm{r}=0.388, \mathrm{p}<0.001)$, average oxygen desaturation $(\mathrm{r}=0.258, \mathrm{p}=0.019)$, oxygen desaturation index $(\mathrm{r}=0.281, \mathrm{p}=0.010)$, length of time spent with an oxygen saturation $<90 \%(r=0.248, p=0.024)$ and arousal index $(r=0.220, p=0.046)$. Plasma fibrinogen levels were negatively correlated with average oxygen saturation during sleep $(r=-0.254, p=0.029)$. Multipl linear regression analyses showed that high ESS and BMI were related with elevated plasma fibrinogen levels, independent of apne hipopne index. In conclusion we suggest that plasma fibrinogen levels correlate with BMI and ESS. The association between plasma fibrinogen levels and nocturnal desaturation supports the linkage between hypoxia and inflamation. We conclude that fibrinogen may be an important factor for development of vascular disease in patients with OSAS.
\end{abstract}

Key Words: Obstructive sleep apnea syndrome (OSAS). Fibrinogen. Epworth sleepiness scale (ESS). Hypoxia. Vasculer disease.

Geliș Tarihi: 11 Kasım 2019

Kabul Tarihi: 27 Kasım 2019

* "18th Congress of the Asian Pacific Society of Respirology" Kongresi'nde sözlü bildiri olarak sunulmuştur (11-14 Kasım 2013, Yokohama/Japonya)
Dr. Ezgi DEMIRDÖĞEN

Bursa Uludağ Üniversitesi Tıp Fakültesi,

Göğüs Hastalıkları Anabilim Dalı,

Görükle, Nilüfer / Bursa

Tel.: 02242950915

E-posta: demirdogenezgi@gmail.com 


\section{E. Demirdöğen, ark.}

Obstrüktif uyku apne sendromu (OUAS); uyku boyunca tekrarlayan üst solunum yolu obstrüksiyonu, intermittant arteriyel oksijen desaturasyonu ve solunum eforunda artışla karakterize bir sendromdur. OUAS etiyolojisinde yaygın lokal ve sistemik inflamasyon varlığı kesindir. Otonom sinir sistemi, hipoksemi-reoksijenizasyon siklusu, inflamasyon ve koagülasyon-fibrinoliz dengesizliği etiyolojide rol oynamaktadır. OUAS komplikasyonları içinde en çok morbidite ve mortalite vasküler komplikasyonlara aittir. OUAS; yüksek dansiteli lipoproteinlerde artış, yüksek C-reaktif protein (CRP), lökosit adezyon faktörlerinde artış, yüksek homosistein, glukoz intolerans1 gibi birçok vasküler risk faktörü ile ilişkili olduğundan, vasküler morbidite ile OUAS ilişkisi sürpriz değildir $^{1-7}$.

Karaciğerden sentezlenen bir plazma proteini olan fibrinojen, koagülasyonda rol oynamakla birlikte, akut faz protein olarak infeksiyon ve inflamasyon yanıtında da artar. Yüksek fibrinojen değerleri hem aterogenezisdeki inflamatuar süreç için belirteç olup, aynı zamanda trombüs formasyonu yoluyla koroner arter hastalığına yol açmaktadır ${ }^{8,9}$. Bir metaanalizde fibrinojen düzeyleri ile koroner kalp hastalığ 1 , inme ve diğer vasküler/nonvasküler mortalite arasında güçlü bir ilişki olduğu gösterilmiştir ${ }^{10}$. Fibrinojen seviyesinde 100 mg / dl'lik uzun süreli bir artış majör kardiyovasküler hastalık riskinde yaklaşık iki kat artış ile ilişkilendirilmiştir ${ }^{10}$. Diğer risk faktörlerinden bağıms1z olarak fibrinojen yüksekliğinin kardiyovasküler mortaliteyle ilişkili olduğuna dair ilk net epidemiyolojik veri Maede ve ark. tarafindan yapılan çalışma ile bildirilmiştir ${ }^{11}$.

İntermittant hipoksi ve bununla ilişkili sempatik aktivasyon OUAS fizyolojisinin temelidir. Sempatik aktivasyon ve hipoksinin hemostatik sistem üzerindeki etkilerini araştırmak, OUAS'da vasküler hastalıklara hemostatik sistemin katkısını anlamak açısından önemlidir. OUAS'lı hastalarda yüksek fibrinojen değerlerini açıklayan mekanizma çok net değildir. Çalışmamızda yeni OUAS tanısı almış hastalarda ve non-apneik olgularda plazma fibrinojen düzeylerini karşılaştırmayı ve polisomnografi (PSG) parametreleri ile ilişkisini değerlendirmeyi amaçladık.

\section{Gereç ve Yöntem}

\section{Çalışma Populasyonu}

Çalışma grubu, horlama, tanıklı apne ya da gündüz aşırı uykululuk hali (GAUH) nedeni ile uyku laboratuvarına refere edilen olgulardan oluşmaktadır. Tüm gece PSG sonuçlarına göre yeni orta ve ağır OUAS tanısı almış 50 hasta 'OUAS grubu', basit horlama olarak değerlendirilen 33 hasta 'kontrol grubu' olarak çalışmaya dahil edilmiştir. Yaşı 18 altında, alkol ve ilaç kötüye kullanımı, serebrovasküler hastalık (SVH), malignensi, kronik pulmoner hastalık, psikiyatrik hastalık, koagülopati, trombosit fonksiyon bozukluğu olan hastalar, gebe, infeksiyöz hastalığı bulunanlar, halihazırda antikoagülan tedavi kullanan ve sedimentasyon değeri yüksek ( $>15 \mathrm{~mm} / \mathrm{h})$ olgular çalışma dişı bırakılmıştır. Çalışma, üniversite etik komitesi tarafınca kabul edilmiştir (KB/173/2003). Tüm katılımcılardan yazılı onam alınmıştır. Olgularda uykululuk, Epworth Uykululuk Skalası (EUS) Türkçe versiyonu ile değerlendirilmiştir ${ }^{12}$. Demografik özellikler, komorbiditeler, almakta olduğu medikal tedaviler ve antropometrik veriler (boy, ağırlık, beden kitle indeksi [BKİ; $\mathrm{kg} / \mathrm{m}^{2}$ ] uyku merkezimize başvurduğunda kayıt altına alınmıştır.

\section{Uyku Çalışması}

Tüm gece PSG çalışması tüm hastalara yapılmşıtır (Compumedics P-series Sleep System; Melbourne, Australia). PSG bileşenleri ise; iki EEG (C3/A2 and O2/A1) kanalı, iki elektorokülogram (EOG) kanalı, bir submental elektromiyogram (EMG), bir elektrokardiyogram (EKG), ve oronazal termistor ile hava akımı olarak siralanmaktadır. Oksijen saturasyonu parmak oksimetre ile ölçülmüş olup, solunumsal hareketler, indüktif pletismograf ile göğüs, karın ve vücut pozisyonu kaydedilmiştir. Tüm hastalar uyku laboratuvarına 20.30'da gelmiş ve PSG'ye yaklaşık 22.30'da başlanmıştır. Uyku skorlaması Amerikan Uyku Tıbbı Akademisi (AASM) standart kriterlerine göre yapılmıştır ${ }^{13}$. Oronazal hava akımının en az 10s tam kesilmesi apne, hava akımında $\% 30$ ve üzerinde kesilme ile birlikte oksihemoglobin saturasyonunda \%3 ve üzeri azalma hipopne olarak tanımlanmıştır. Apne ve hipopne toplam süresinin toplam uyku süresine (TUS) bölünmesi ile apne hipopne indeksi (AHI) elde edilir. Çalışmamızda, AHI $\geq 15$ olanlar 'OUAS grup', $\mathrm{AHI}<5$ olanlar 'kontrol grubu' olarak iki gruba ayrılmıştır. Oksijen desaturasyon indeksi (ODİ) 3 ve ODİ 2 ise, sirasıyla uyku süresince saatte $\% 3$ ile $\% 2$ ve üzeri desaturasyon ortalama sayısıdır.

\section{Fibrinojen Düzeylerinin Ölçülmesi}

Uyku laboratuvarında sabah 08.00-09.00 arasında alınan açlık venöz kan örnekleri toplanmıştır. Örnekler hızlıca laboratuvara ulaştırılmış ve $1500 x g$, en az 10 dk santrifüj edilmiştir. Plazma örnekleri ölçüm yapılana dek $15-25^{\circ} \mathrm{C}$ 'de maksimum 8 saat depolanmıştır. Fibrinojen düzeyleri, biyokimya laboratuvarında Dade Behring Multifibren $U$ kit kullanılarak modifiye Clauss metodu ile ölçülmüştür. Fibronojen konsantrasyonu, sitratlı plazma örneklerinde her iki cinsiyet için 1.8-3.5 g/L referans aralığ

\section{Biyoistatistiksel Analiz}

Verinin normal dağılım gösterip göstermediği Shapiro-Wilk testi ile incelenmiştir. Normal dağılım gösteren veri için iki grup karşılaştırmalarında t-testi uygu- 


\section{Obstruktif Uyku Apne Sendromu ve Fibrinojen}

lanmıștır. Değișkenler arasındaki ilișkiler Pearson korelasyon katsayısı ile incelenmiştir. Kategorik verinin incelenmesinde Pearson Ki-kare testi ve Fisher'in Kesin Ki-kare testi kullanılmıştır. Çoklu regresyon analizi ile fibrinojen ve BKİ, AHİ, EUS skoru arasındaki ilişki incelenmiştir. Anlamlılık düzeyi $\alpha=0.05$ olarak belirlenmiştir. Verinin istatistiksel analizi SPSS23.0 (IBM Corp. Released 2015. IBM SPSS Statistics for Windows, Version 23.0. Armonk, NY: IBM Corp.) istatistik paket programında yapılmıştır.

\section{Bulgular}

\section{Temel Karakteristik Özellikler}

Çalışma grubuna art arda yeni tanı almış 50 orta/ağır OUAS $(A H \dot{I} \geq 15)$ ve 33 non-apneik $(A H \dot{I}<5)$ hasta dahil edilmiştir. Her iki grupta demografik ve klinik özellikler Tablo I'de gösterilmektedir. Her iki grupta yaş, cinsiyet ve sigara alışkanlığı açısından fark bulunmamıştır $(p=0.270, p=0.134, p=0.233$, sırasıyla). OUAS grubunda BKİ ve EUS skoru daha yüksektir $(p=0.04, p<0.001$, sirasiyla). Hipertansiyon OUAS grubunda daha sık saptanmış iken, diabetes mellitus (DM) ve koroner arter hastalığı (KAH) oranları aç1sından iki grup arasında fark yoktur. Her iki gruba ait polisomnografik özellikler Tablo II'de özetlenmiştir. Her iki grup arasında uyku evresi 3, AHI, apnehipopne süresi, arousal indeksi, uyku süresince ortalama oksijen saturasyonu, oksijen saturasyonu \%90 altında geçen süre, ODİ 2 ve ODİ 3 değerleri açısından anlamlı fark olduğu saptanmıştır (Tablo II).

Tablo I. OUAS ve kontrol grubunun klinik karakteristik özellikleri

\begin{tabular}{|l|c|c|c|}
\hline & $\begin{array}{c}\text { OUAS } \\
(\mathbf{n}=50)\end{array}$ & $\begin{array}{c}\text { Kontrol } \\
(\mathbf{n}=33)\end{array}$ & $\mathbf{P}$ \\
\hline Yaş (yıl) & $49.60 \pm 1.42$ & $47 \pm 2.00$ & 0.270 \\
\hline Erkek/Kadın & $43 / 7$ & $24 / 9$ & 0.134 \\
\hline BKi $\left(\mathrm{kg} / \mathrm{m}^{2}\right)$ & $32.00 \pm 0.90$ & $29.20 \pm 0.64$ & 0.040 \\
\hline Sigara içen/içmeyen & $34 / 16$ & $17 / 14$ & 0.233 \\
\hline Sigara paket yılı & $15.64 \pm 2.19$ & $10.35 \pm 2.40$ & 0.124 \\
\hline Koroner Arter Hastalığı & $3 / 47$ & $4 / 29$ & 0.420 \\
\hline Hipertansiyon & $23 / 27$ & $6 / 27$ & 0.009 \\
\hline Diabetes Mellitus & $8 / 42$ & $1 / 32$ & 0.080 \\
\hline ESS & $10.5 \pm 0.79$ & $4.7 \pm 0.61$ & $<0.001$ \\
\hline
\end{tabular}

BKI: beden kitle indeksi

(Değerler ortalama \pm standart hata olarak verildi)

\section{Plazma Fibrinojen Düzeyleri}

Plazma fibrinojen düzeyleri OUAS grubunda kontrol gruba göre anlamlı yüksektir [(4.2 $\pm 0.14 \mathrm{~g} / \mathrm{L})$ vs (3.6 $\pm 0.17 \mathrm{~g} / \mathrm{L}),(\mathrm{p}<0.028)$, sırasıyla] (Şekil 1). Fibrinojen düzeyleri sigara içen ve içmeyen grupta benzer olup $(\mathrm{p}=0.903)$, yaş $(\mathrm{r}=0.327, \mathrm{p}=0.003)$, BKİ $(\mathrm{r}=0.388$, $\mathrm{p}<0.001)$ ve EUS skoru $(\mathrm{r}=0.301, \mathrm{p}=0.006)$ ile pozitif korele bulunmuştur. Fibrinojen düzeyleri ile AHI ve apne-hipopne süresi arasında anlamlı ilişki saptanma- mıştır. Plazma fibrinojeni, ortalama oksijen desaturasyonu ( $\mathrm{r}=0.258, \mathrm{p}=0.019)$, ODİ2 $(\mathrm{r}=0.281, \mathrm{p}=0.010)$, oksijen saturasyonu $\% 90$ altında geçen süre $(\mathrm{r}=0.248$, $\mathrm{p}=0.024)$ ve arousal indeks $(\mathrm{r}=0.220, \mathrm{p}=0.046)$ ile pozitif korele iken, uykuda ortalama oksijen saturasyonu ile negatif korele bulunmuştur $(r=-0.254$, $\mathrm{p}=0.029$ ) (Tablo III). Çoklu doğrusal regresyon analiz ile EUS skoru ve BKİ'nin, AHİ'den bağımsız olarak, fibrinojen düzeyleri ile ilişkili değişkenler olduğu saptanmıştır (Tablo IV).

Tablo II. OUAS ve kontrol grubunun polisomnografik parametrelerinin karşılaştırılması

\begin{tabular}{|l|c|c|c|}
\hline & OUAS & Kontrol & P \\
\hline $\begin{array}{l}\text { Evre 3 (\%toplam uyku } \\
\text { süresi) }\end{array}$ & $7.2 \pm 1.04$ & $16.5 \pm 1.42$ & $<0.001$ \\
\hline $\begin{array}{l}\text { Hızlı göz hareketleri } \\
\text { (\%total uyku süresi) }\end{array}$ & $15.2 \pm 1.20$ & $16.5 \pm 1.16$ & 0.480 \\
\hline AHi & $48.7 \pm 3.28$ & $1.3 \pm 0.21$ & $<0.001$ \\
\hline Apne-hipopne süresi (dk) & $139.7 \pm 11.29$ & $2.1 \pm 0.38$ & $<0.001$ \\
\hline Arousal indeksi & $29 \pm 2.06$ & $14.6 \pm 1.57$ & $<0.001$ \\
\hline $\begin{array}{l}\text { Uykuda ortalama oksijen } \\
\text { satürasyonu (\%) }\end{array}$ & $86.8 \pm 1.09$ & $95.1 \pm 0.32$ & $<0.001$ \\
\hline Ortalama desatürasyon (\%) & $9.9 \pm 0.66$ & $3.7 \pm 0.53$ & $<0.001$ \\
\hline $\begin{array}{l}\text { Oksijen satürasyonunun \% } \\
\text { 90'In altında kalma süresi }\end{array}$ & $82.8 \pm 12.93$ & $1 \pm 0.55$ & $<0.001$ \\
\hline ODi 2 & $79.2 \pm 3.40$ & $26.4 \pm 2.82$ & $<0.001$ \\
\hline ODi3 & $68.1 \pm 3.95$ & $11 \pm 1.61$ & $<0.001$ \\
\hline
\end{tabular}

AHI: apne hipopne indeksi, ODİ: oksijen desaturasyon indeksi

Tanımlayıcı istatistikler ortalama \pm standart hata olarak sunulmuştur.

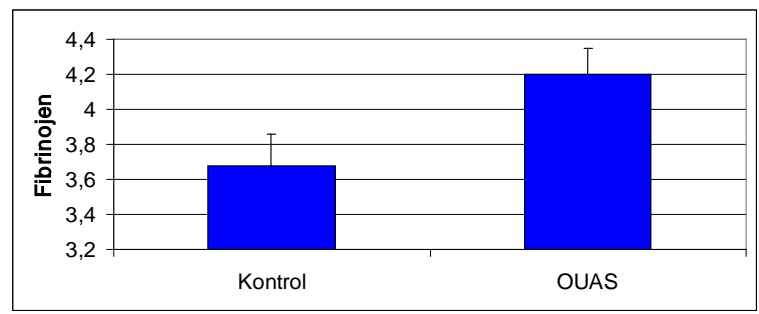

Şekil 1.

OUAS ve kontrol grubunda fibrinojen düzeylerinin karşıllaştırılması

Tablo III. Fibrinojen ve diğer değişkenler arasında korelasyon.

\begin{tabular}{|l|c|c|}
\hline \multirow{2}{*}{ Değişkenler } & \multicolumn{2}{|c|}{ Fibrinojen } \\
\cline { 2 - 3 } & $\mathbf{r}$ & $\mathbf{P}$ \\
\hline Yaş & 0.327 & 0.003 \\
\hline BKI & 0.388 & $<0.001$ \\
\hline ESS & 0.301 & 0.006 \\
\hline Uyanık O2 saturasyonu & -0.229 & 0.037 \\
\hline Uyku O2 saturasyonu & -0.254 & 0.029 \\
\hline Ortalama O2 desaturasyonu & 0.258 & 0.019 \\
\hline $\begin{array}{l}\text { Oksijen satürasyonunun \% 90'ın } \\
\text { altında kalma süresi }\end{array}$ & 0.248 & 0.024 \\
\hline ODi2 & 0.281 & 0.010 \\
\hline ODi3 & 0.252 & 0.022 \\
\hline Arousal indeksi & 0.220 & 0.046 \\
\hline
\end{tabular}

ODİ: Oksijen desaturasyon indeksi 


\section{E. Demirdöğen, ark.}

Tablo IV. Çoklu doğrusal regresyon analizi

\begin{tabular}{|c|c|c|c|}
\hline Değişkenler & $\beta$ & Standart Hata & $p$ \\
\hline Sabit & 1.705 & 0.629 & 0.008 \\
BKi & 0.065 & 0.022 & 0.004 \\
AHI & -0.005 & 0.005 & 0.29 \\
EUS & 0.050 & 0.024 & 0.04 \\
\hline
\end{tabular}

\section{Tartışma ve Sonuç}

Çalışmamızda OUAS grubunda plazma fibrinojen düzeyleri kontrol gruba göre anlamlı düzeyde yüksek bulunmuştur. Plazma fibrinojen düzeyleri ile EUS skoru ve BKİ arasında anlamlı pozitif korelasyon gözlenmiştir. Fibrinojen düzeyleri ile ODİ2, ODİ3, ortalama oksijen desaturasyonu, oksijen satürasyonunun \% 90'ın altında geçen süre arasında anlamlı pozitif korelasyon, fibrinojen düzeyleri ile uykudaki ve uyanıklıktaki oksijen saturasyonu arasında negatif ilişki bulunmuştur. Bu çalışmada EUS skoru ve BKİ'nin, AHİ'den bağımsız olarak, fibrinojen düzeyleri ile ilişkili değişkenler olduğu belirlenmiştir.

OUAS, kardiyovasküler hastalıklar ve sistemik hipertansiyon için en önemli risk faktörlerinden biridir ${ }^{14-16}$. Orta ve ağır şiddette OUAS olan hastalarda sol ventrikül hipertrofisi ve diyastolik disfonksiyon prevelansı $\operatorname{artmıştır~}^{17,18}$. Ayrıca generalize aterosklerozun belirtisi olan karotid ateroskleroz ile OUAS arasında da bir ilişki olduğu doğrulanmıştır ${ }^{19}$. McArdle ve ark., ${ }^{20}$ OUAS ve geçici iskemik atak arasında güçlü bir ilişki olmadığını belirtmekle birlikte aynı çalışmada yüksek fibrinojen düzeyleri, miyokardiyal enfarktüs ve sigara içimi öyküsü ile geçici iskemik atak arasında ilişki olduğu saptanmıştır. Akut iskemik inmeli hastalarda uyku apne varlığı, artmış CRP ve fibrinojen düzeyleri ile bağımsız olarak ilişkili bulunmuştur ${ }^{21}$.

Uyku fragmantasyonu, uyku deprivasyonu ve metabolik bozukluklar yanında OUAS'ta tipik patern olan intermitant hipoksi ve reoksinejizasyon, inflamatuar sürecin başlamasında major faktördür. İntermittant hipoksi, kardiyovasküler patogenezde önemli rol oynamaktadır. Peled ve ark., ${ }^{22}$ sedimentasyon, CRP ve fibrinojenden oluşan üç inflamasyon belirtecini de OUAS grubunda kontrol grubuna göre yüksek saptamışlardır. Sözü geçen araştırmada OUAS grubunda eritrosit adezyon ve agregasyonu kontrol grubuna göre daha güçlü bulunmuştur. Bu sonuçların kardiyovasküler morbiditeyi açıklayabileceği öne sürülmüştür. Yapılan çalışmalarda inflamatuar belirteçler ve obezite ile GAUH arasındaki ilişki AHI'den daha güçlü bulunmuştur ${ }^{23-25}$. Bizim çalışmamızda da EUS ve BKİ'nin fibrinojen düzeyleri ile AHİ'den bağımsız olarak ilişkili olduğu saptanmıştır. Obezite, özellikle visseral adipozite kronik düşük dereceli inflamasyonla ilişkilidir. Obez kadınlarda ve birinci derece akrabalarında yapılmış bir çalışmada artmış CRP ve fibrinojen düzeyleri, BKİ ve bel çevresi ile ilişkili bulunmuştur ${ }^{26}$. Ayrıca OUAS tanılı obez hastalarda, OUAS olmayan obezlere göre daha yüksek CRP ve fibrinojen değerleri gösterilmiştir ${ }^{27}$. GAUH'nin birçok nedeni vardır ve oldukça yaygın bir sorundur. Bixler ve ark. ${ }^{28}$ orijinal bir populasyonda GAUH prevelansını cinsiyet fark1 olmaksızın \%8.7 saptamışlardır. Gündüz aşırı uykululuk skoru ve apne şiddeti arasındaki ilişki göreceli olarak zayıftır. Populasyon bazlı çalışmalarda aşırı uykululuğun, OUAS'lı bireylerin çoğunda major şikayet olmadığ 1 da görülmüştür ${ }^{29,30}$. Bizim çalışmamızda da EUS skoru, AHİ'den bağımsız olarak fibrinojen düzeyleri ile ilişkili bulunmuştur.

OUAS'ta inflamasyonda ve koagülasyon profilinde özellikle sitokinler ve fibrinojende bozukluk gelişmektedir $^{31}$. Çalışmalar göstermiştir ki OUAS'ta, trombosit aktivitesinde artış, pıhtılaşma faktörlerinde artış ve fibrinolizde bozulma sonucu ortaya çıkan hiperkoagülan bir durum mevcuttur ${ }^{32,33}$. Bu hiperkoagülan durumda olası mekanizma ise uyku boyunca tekrarlayan apneik olayların katekolamin düzeylerinde artışla açıklanan sempatik sinir sistemi aktivitesini $\operatorname{arttırmasidır}^{34}$. OUAS'ta tromboz riskinin arttığ 1 , platelet agregasyonu ve aktivasyonunda artış olması, yükselmiş fibrinojen düzeyleri ve fibrinolitik aktivitede azalma ile kanıtlanmıștır ${ }^{35,36}$.

OUAS'lı hastalarda uvula mukozasında interstisyel ödem ve plazma hücre infiltrasyonu nedeniyle hastalığın plazma fibrinojen düzeylerinin yükselmesine neden olabileceği ileri sürülmüştür. Yumuşak damak inflamasyonu uyku boyunca üst havayolu oklüzyonuna katkıda bulunmaktadır ${ }^{37}$. Yapılan bir araştırmada, ${ }^{36}$ iskemik inme saptanan hastalarda OUAS prevelans1nın arttığ1 ve hatta OUAS olan inmeli hastalarda fibrinojen düzeylerinin yüksek olduğu gösterilmiştir. Bahsi geçen çalışmada OUAS, yüksek fibrinojen düzeyleri ile bağımsız olarak ilişkili bulunmuştur. Ayrıca fibrinojen düzeyleri; RDİ, en uzun apne süresi ve ortalama oksijen desaturasyonu ile pozitif korele, ortalama minimum oksijen saturasyonu ile negatif korele bulunmuştur. Wessendorf ve ark., ${ }^{36}$ OUAS’ta artan inme riskinde olası mekanizmanın fibrinojen düzeyleri ile ilişkili olabileceğini belirtmişlerdir. Bu nedenle bizim çalışmamızda, inme tanısı ya da öyküsü olan olgular dışlanmıştır. Nobili ve ark., ${ }^{38}$ OUAS'lı vakalarda sabah ölçülen fibrinojen düzeylerini yüksek saptamışlardır. Bir başka araştırmada, OUAS'lı hastalarda sabah fibrinojen düzeyleri öğleden sonra bakılan değerlere göre yüksek bulunmuştur ${ }^{39}$. Sabahları yüksek saptanan fibrinojen seviyesinin sürekli pozitif hava yolu basıncı (CPAP) tedavisi sonrası düştüğü gözlenmiştir. Başka bir çalışmada plazma viskozitesi ve fibrinojen değerleri, diürinal farklılık olmaksızın OUAS grubunda daha yüksek saptanmışken, CPAP tedavisi ile fibrinojen düzeylerinde değișiklik gözlenmemiştir ${ }^{40}$. Bizim çalışmamızda da OUAS grubunda fibrinojen değerleri kontrol grubuna göre anlamlı 


\section{Obstruktif Uyku Apne Sendromu ve Fibrinojen}

düzeyde yüksek bulundu. Ancak CPAP tedavisi sonrasındaki fibrinojen düzeyleri değerlendirilmedi. Kaditis ve ark. ${ }^{41}$ tarafindan, uykuda solunum bozukluğu (horlaması olan AHİ $>5$ olgular ile horlaması olan AHI $<5$ hastalar) olan çocuklarda yapılan bir çalışmada, horlaması olan çocuklarda fibrinojen değerleri kontrol grubuna (sadece horlama) göre yüksek bulunmuş, fakat fibrinojen değerleri ile AHI ve diğer PSG parametreleri arasında korelasyon saptanmamıştır. Erişkinlerde yapılan bir araştırmada, bizim bulgularımızla uyumlu olarak fibrinojen düzeyleri OUAS olgularında kontrol gruba göre anlamlı yüksek bulunmuş, ve fibrinojen ile ortalama oksijen saturasyonu arasında negatif ilişki gösterilmiştir ${ }^{42}$. Ancak bahsi geçen araştırmada bizim sonuçlarımızın aksine AHİ ile fibrinojen değerleri doğrudan ilişskili bulunmuştur ${ }^{42}$.

Çalışmamızın birtakım kısıtlılıkları mevcuttur. Fibrinojen düzeyleri sadece sabah ölçülmüş ve CPAP tedavisi uygulanan olguların tedavi sonrası plazma fibrinojen düzeyleri kontrol edilmemiştir.

Sonuç olarak bu çalışmada AHİ ile fibrinojen düzeyleri arasında anlamlı ilişki olmamakla birlikte plazma fibrinojen düzeyleri OUAS grubunda kontrol grubuna göre anlamlı olarak yüksektir. EUS skoru ve BKİ'nin AHI'den bağımsız olarak, fibrinojen düzeyleri ile ilişkili olduğu saptanmıştır. Ayrıca plazma fibrinojen düzeyleri ile nokturnal desaturasyon arasındaki pozitif korelasyon, hipoksi ve inflamasyon ilişkisini desteklemektedir. Önemli nokta, OUAS'ta fibrinojenin vasküler risk faktörü olabileceğinin göz önünde bulundurulması gerektiğidir. Unutulmamalıdır ki, OUAS tanılı hastalarda major sağlık yükü, sistemik arteriyel hipertansiyon, koroner arter hastalığı, kalp yetmezliği, inme gibi artmış kardiyovasküler risk ile ilişkilidir.

\section{Kaynaklar}

1. Börgel J, Sanner BM, Bittlinsky A, et al. Obstructive sleep apnoea and its therapy influence high-density lipoprotein cholesterol serum levels. Eur Respir J 2006;27:121-7.

2. Can M, Açıkgöz S, Mungan G, et al. Serum cardiovascular risk factors in obstructive sleep apnea. Chest 2006;129:233-7.

3. Zouaoui Boudjeltia K, Van Meerhaeghe A, Doumit S, et al Sleep apnoea-hypopnoea index is an independent predictor of high-sensitivity C-reactive protein elevation. Respiration 2006;73:243-6.

4. Dyugovskaya L, Lavie P, Lavie L. Increased adhesion molecules expression and production of reactive oxygen species in leukocytes of sleep apnea patients. Am J Respir Crit Care Med 2002;165:934-9.

5. Lavie L, Vishnevsky A, Lavie P. Evidence for lipid peroxidation in obstructive sleep apnea. Sleep 2004;27:123-8.

6. Reichmuth KJ, Austin D, Skatrud JB, Young T. Association of sleep apnea and type II diabetes: a population-based study. Am J Respir Crit Care Med 2005;172:1590-5.

7. Harsch IA, Schahin SP, Radespiel-Tröger M, et al. Continuous positive airway pressure treatment rapidly improves insulin sensitivity in patients with obstructive sleep apnea syndrome. Am J Respir Crit Care Med 2004;169:156-62.
8. Meade TW. Fibrinogen measurement to assess the risk of arterial thrombosis in individual patients: yes. J Thromb Haemost 2005;3:632-4.

9. Rudnicka AR, Mt-Isa S, Meade TW. Associations of plasma fibrinogen and factor VII clotting activity with coronary heart disease and stroke: prospective cohort study from the screening phase of the Thrombosis Prevention Trial. Journal of Thrombosis and Haemostasis 2006,4:2405-10.

10. Danes J, Lewington S, Thompson SG, et al. Plasma fibrinogen level and the risk of major cardiovascular diseases and nonvascular mortality: an individual participant meta-analysis. JAMA 2005;294:1799-809.

11. Meade TW, North WR, Chakrabarti R, et al. Haemostatic function and cardiovascular death: early results of a prospective study. Lancet 1980;1:1050-4.

12. Izci B, Ardic S, Firat H, Sahin A, Altinors M, Karacan I. Reliability and validity studies of the Turkish version of the Epworth Sleepiness Scale. Sleep Breath. 2008 May;12(2):161-8.

13. Berry RB, Budhiraja R, Gottlieb DJ, et al.; American Academy of Sleep Medicine.

les for scoring respiratory events in sleep: update of the 2007 AASM Manual the Scoring of Sleep and Associated Events. Deliberations of the Sleep Apnea Definitions Task Force of the American Academy of Sleep Medicine. J Clin Sleep Med. 2012 Oct 15;8(5):597-619. doi: 10.5664/jcsm.2172.

14. Shahar E, Whitney CW, Redline S, et al. Sleep-disordered breathing and cardiovascular disease: cross-sectional results of the Sleep Heart Health Study. Am J Respir Crit Care Med 2001;163:19-25.

15. Somers VK, White DP, Amin R, et al. Sleep apnea and cardiovascular disease: an American Heart Association/american College Of Cardiology Foundation Scientific Statement from the American Heart Association Council for High Blood Pressure Research Professional Education Committee, Council on Clinical Cardiology, Stroke Council and Council On Cardiovascular Nursing. In collaboration with the National Heart, Lung and Blood Institute National Center on Sleep Disorders Research (National Institutes of Health). Circulation 2008;118:1080-111.

16. Davies CW, Crosby JH, Mullins RL, et al. Case-control study of 24 hour ambulatory blood pressure in patients with obstructive sleep apnoea and normal matched control subjects. Thorax 2000;55:736-40.

17. Baguet JP, Hammer L, Levy P, et al. Night-time and diastolic hypertension are common and underestimated conditions in newly diagnosed apnoeic patients. J Hypertens 2005;23:521-7.

18. Fung JW, Li TS, Choy DK, et al. Severe obstructive sleep apnea is associated with left ventricular diastolic dysfunction. Chest 2002;121:422-9.

19. Drager LF, Bortolotto LA, Lorenzi MC, et al. Early signs of atherosklerosis in obstructive sleep apnea. Am J Respir Crit Care Med 2005; 172:613-8.

20. McArdle N, Riha RL, Vennelle M, et al. Sleep-disordered breathing as a risk factor for cerebrovascular disease: a casecontrol study in patients with transient ischemic attacks. Stroke 2003;34:2916-21.

21. Dziewas R, Ritter M, Kruger L, et al. C-reactive protein and fibrinogen in acute stroke patients with and without sleep apnea. Cerebrovasc Dis 2007;24:412-7.

22. Peled N, Kassirer M, Kramer MR, et al. Increased erythrocyte adhesiveness and aggregation in obstructive sleep apnea syndrome. Thromb Res 2008;121:631-6.

23. Sanders $\mathrm{MH}$, Givelber R. Sleep disordered breathing may not be an independent risk factor for diabetes, but diabetes may contribute to the occurrence of periodic breathing in sleep. Sleep Med 2003;4:349-50.

24. Sharma SK, Kumpawat S, Goel A, et al. Obesity, and not obstructive sleep apnea, is responsible for metabolic abnormali- 


\section{E. Demirdöğen, ark.}

ties in a cohort with sleep-disordered breathing. Sleep Med 2007;8:12-7.

25. Sharma SK, Mishra HK, Sharma H, et al. Obesity, and not obstructive sleep apnea, is responsible for increased serum hsCRP levels in patients with sleep-disordered breathing in Delhi. Sleep Med 2008;9:149-56.

26. Saraç F, Özgen GA, YIlmaz C, Tüzün M. Cardiovascular risk factors in obese women and their first-degree relatives. Anadolu Kardiyol Derg 2007;7: 371-7.

27. Basoglu OK, Sarac F, Sarac S, Uluer H, Yilmaz C. Metabolic syndrome, insulin resistance, fibrinogen, homocysteine, leptin, and C-reactive protein in obese patients with obstructive sleep apnea syndrome. Ann Thorac Med. 2011 Jul;6(3):120-5. doi: 10.4103/1817-1737.82440.

28. Bixler EO, Vgontzas AN, Lin HM, et al. Excessive daytime sleepiness in a general population sample: the role of sleep apnea, age, obesity, diabetes, and depression. J Clin Endocrinol Metab 2005;90:4510-5.

29. Reishtein JL, Pack AI, Maislin G, et al. Sleepiness and relationships in obstructive sleep apnea. Issue Mental Health Nurs 2006;27:319-30.

30. Kapur VK, Baldwin CM, Resnick HE, et al. Sleepiness in patients with moderate to severe sleep-disordered breathing. Sleep 2005;28:472-7.

31. Shamsuzzaman ASM, Somers VK. Fibrinogen, stroke and obstructive sleep apnea. Am J Respir Crit Care Med 2000;162:2018-20.

32. Rosito GBA, Tofler GH. Hemostatic factors as triggers of cardiovascular events. Cardiol Clin 1996;14:239-50.

33. Koenig W. Hemostatic risk factors for cardiovascular diseases. Eur Heart J 1998;19:39-43.
34. Dimsdale JE, Coy T, Ziegler MG et al. The effect of sleep apnea on plasma and urinary catecholamines. Sleep 1995;18:377-81.

35. Bokinsky G, Miller M, Ault K, Husband P, Mitchell J. Spontaneous platelet activation and aggregation during obstructive sleep apnea and its response to therapy with nasal continuous positive airway pressure: a preliminary investigation. Chest 1995;108:625-30.

36. Wessendorf TE, Thilmann AF, Wang YM, et al. Fibrinogen levels and obstructive sleep apnea in ischemic stroke. Am J Respir Crit Care Med 2000;162:2039-42.

37. Sekosan M, Zakkar M, Wenig BL, Olopade CO, Rubinstein I. Inflammation in the uvula mucosa of patients with obstructive sleep apnea. Laryngoscope 1996;106:1018-20.

38. Nobili L, Schiavi G, Bozano E, et al. Morning increase of whole blood viscosity in obstructive sleep apnea syndrome. Clin Hemorheol Microcirc 2000;22:21-27.

39. Chin K, Ohi M, Kita H, et al. Effects of NCPAP therapy on fibrinogen levels in obstructive sleep apnea syndrome. Am J Respir Crit Care Med 1996;153:1972-6.

40. Reinhart WH, Oswald J, Walter R, Kuhn M. Blood viscosity and platelet function in patients with obstructive sleep apnea syndrome treated with nasal continuous positive airway pressure. Clin Hemorheol Microcirc 2002;27:201-7.

41. Kaditis AG, Alexopoulos EI, Kalampouka E, et al. Morning levels of fibrinogen in children with sleep-disordered breathing. Eur Respir J 2004;24:790-7.

42. Shamsuzzaman A, Amin RS, Calvin AD, Davison D, Somers VK. Severity of obstructive sleep apnea is associated with elevated plasma fibrinogenin otherwise healthy patients. Sleep Breath. 2014 Dec;18(4):761-6. doi: 10.1007/s11325-014-09384. 